\title{
Numerical simulation on oil rim impact on underground gas storage injection and production
}

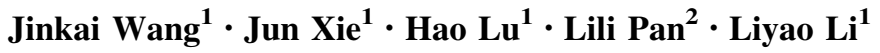

Received: 6 July 2015/Accepted: 21 September 2015/Published online: 3 October 2015

(c) The Author(s) 2015. This article is published with open access at Springerlink.com

\begin{abstract}
A large number of underground gas storage operating experience shows: the oil rim has a great impact on gas injection and production. Here, the underground gas storage in the Dagang Oilfield (G393) was taken as an example to study the oil rim impact mechanism. Firstly, the G393 gas reservoir developmental history was simulated, based thereon, the equations governing the distribution of gas, oil, and water in the reservoir before building the storage injection and production equipment was established. Then, the oil rim impact mechanism on the gas seepage of underground gas storage operation was studied using numerical simulation method and the factors affecting oil recovery from the oil rim for the gas diffusion were outlined. The result shows that oil rim may prevent seepage of gas, resulting in a one-way gas onrush, thus affecting the smooth operation of underground gas storage. In addition, crude oil recovery in the oil rim may affect the gas well's production capacity, the lower the degree of recovery of crude oil, the harder for the underground gas storage to run quickly and smoothly. Finally, the most appropriate injection wells for the G393 fault-block gas storage were designed, by which process the oil production period was shortened to 8 years, ensuring stable and efficient operation of the underground gas storage.
\end{abstract}

Jinkai Wang

wangjk@sdust.edu.cn

1 College of Geological Science and Engineering, Shandong University of Science and Technology, Qingdao 266590, Shandong Province, China

2 Research Institute of Exploration and Development, Jilin Oilfield, Songyuan 138000, Jilin, China
Keywords Underground gas storage · Dagang Oilfield · G393 fault-block · Oil rim · Water energy

\section{Introduction}

The injection-production mechanism of a watered-out oil rim underground gas storage is relatively complex and is related to three-phase (oil-gas-water) percolation and material exchange: the fluid phase distribution was complex and irregular before the storage was built, because the reservoir was influenced by retrograde condensation, the degassing of crude oil, water injection, and the presence of edge-bottom water ( $\mathrm{Li}$ and Zhang 2000; Ding and Xie 2006; Wang et al. 2014). There is not much specialised research on impact mechanism of oil rim on underground gas storage operation, it is difficult to form an effective reference. However, the process of gas injection into the oil rim can be equivalent to natural gas flooding process. Domestic and foreign scholars have done a lot of laboratory tests and field studies in this aspect, have also made some achievements and describe the change of fluid seepage in the flooding reservoir after gas injection.

From the late 1950s, the US researchers designed a gaswater alternative flooding programme and carried out numerical simulation, initial figured out the phase change and seepage law of the oil gas and water three-phase after the gas injection into the reservoir (Caudle and Dyes 1958). Since then, a lot of scientists have conducted rock physical modelling experiment and numerical simulation studies (Haln and Monger 1990; Wozinak et al. 1997), these basically figure out: when the gas was injected rapidly into the storage, it would cause a series of reactions, such as the instigation of the Jamin effect, flow-around, water-locking, gas-locking, and emptying (Kurihara et al. 2000). These 
factors exert significant effects on production efficiency in underground gas storage facilities (Udegbunan et al. 1994).

The G393 fault-block was a condensate gas reservoir with an oil rim, which had experienced more than 5 years' water-injection development before being converted to an underground gas storage. The reservoir was in the middle of the development and had a complex fluid distribution, in which oil, gas, and water coexisted (Fig. 1).

To improve the running efficiency of this type of underground gas storage, the factors influencing, and the extent of, the oil rim should be studied before any alterations are undertaken. Firstly, a three-dimensional (3-d) dynamic model should be established to simulate the gas reservoir development history and to establish a fluid distribution model before any alterations take place; then using numerical simulation method to study the impact mechanism of oil rim, design different schemes to study the barrier effect of the fluid and the influence degree of the oil rim on gas production capacity, clear the oil, gas and water three-phase seepage rule in the process of underground gas storage rebuilt. Finally, based on the results of numerical simulation, the underground gas storage injection and production scheme can be designed to preferably reasonable performance indicators, provide guidance for the smooth and efficient operation of 393 underground gas storage.

\section{Numerical simulation of gas reservoir development history}

\section{The establishment of a 3-d, three-phase model for $\mathbf{G 3 9 3}$}

The G393 fault-block underground gas storage has been altered by the abandoned condensate gas reservoir within its oil rim. Three-phase flow, including oil, gas, and water, in the reservoir was involved in the development thereof. A numerical simulation of 3-d, three-phase behaviour was, therefore, needed to analyse its development and history. Using Darcy's law and the law of conservation of mass, and considering rock and fluid compressibility, we established a model for flow in a three-dimensional, three-phase, anisotropic, oil reservoir.

The 3-d seepage model governing three-phase continuous seepage is given by:

$$
\left\{\begin{array}{l}
\nabla \cdot\left[M_{o} N_{o}\left(\nabla P_{o}-\rho_{o} G \nabla D\right)\right]+q_{o}=\frac{\partial}{\partial t}\left(S_{o} A_{o}\right) \quad \text { Oil } \\
\nabla \cdot\left[R_{s} M_{o} N_{o}\left(\nabla P_{o}-\rho_{o} G \nabla D\right)+M_{g} N_{g}\left(\nabla P_{g}-\rho_{g} G \nabla D\right)\right] \\
\quad+q_{g}=\frac{\partial}{\partial t}\left(R_{s} S_{o} A_{o}+S_{g} A_{g}\right) \quad \text { Gas } \\
\nabla \cdot\left[M_{w} N_{w}\left(\nabla P_{w}-\rho_{w} G \nabla D\right)\right]+q_{w}=\frac{\partial}{\partial t}\left(S_{w} A_{w}\right) \quad \text { Water }
\end{array}\right.
$$

where $M$ is relative permeability/viscosity; $A$ is porosity/ volume coefficient; $N$ is permeability/volume coefficient; $P$ is pressure; $\rho$ is fluid density; $q$ is fluid flow rate; $S$ is fluid saturation ratio; (the subscripts $\mathrm{o}, \mathrm{g}$, and $\mathrm{w}$ represent the water phase of the oil and gas, respectively). $G$ is acceleration due to gravity; $D$ is depth of the reservoir; $R_{S}$ is dissolved gas oil ratio; $C$ is model boundary. The initial conditions for three-phase equilibrium are as follows:

$$
\left\{\begin{array}{l}
S_{g}+S_{o}+S_{w}=1 \\
P(x, y, z)=P_{0}(x, y, z)
\end{array}\right.
$$

The boundary conditions for the closed boundary are: $\left.\frac{\partial P}{\partial n}\right|_{C}=0$

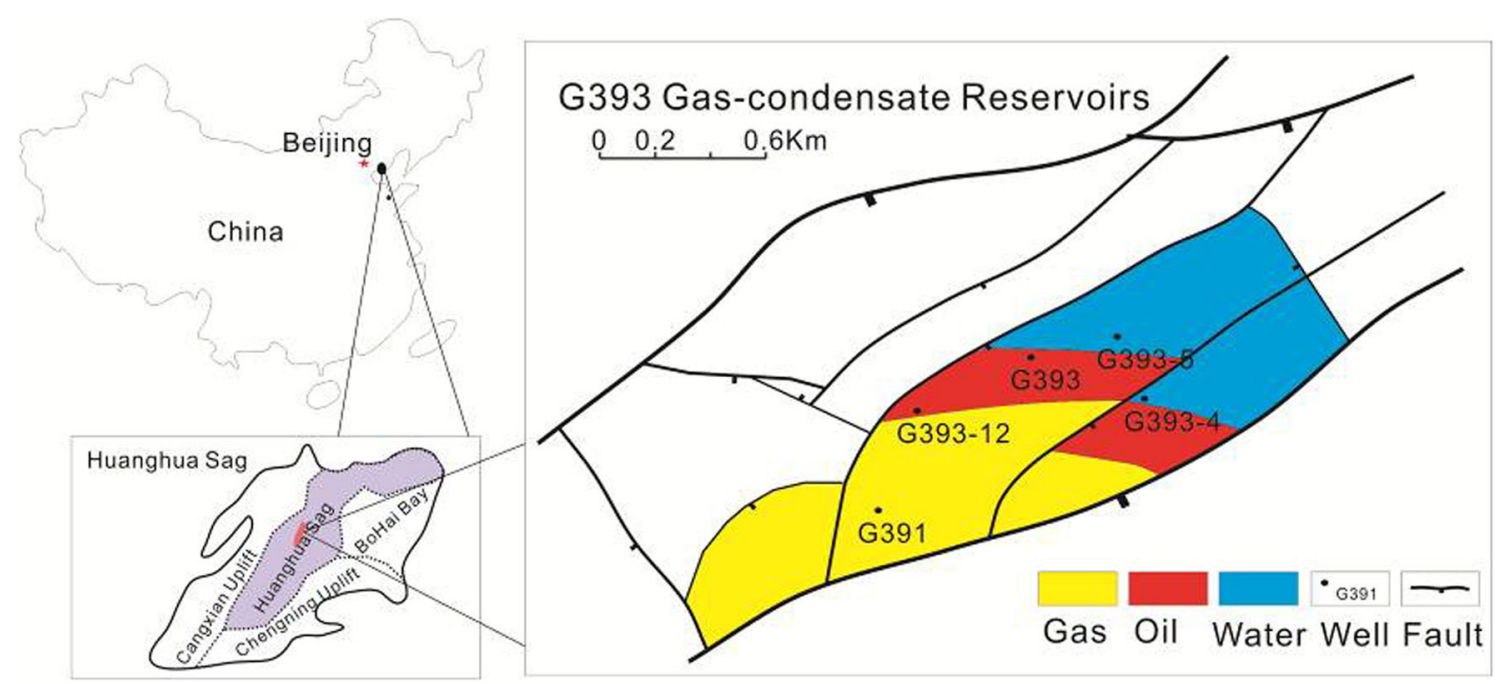

Fig. 1 Location map of the G393 fault-block gas-condensate reservoirs 


\section{Model meshing}

While establishing the 3-d geological model, the grid line of the plan must reflect the heterogeneity of the reservoir, the degree of heterogeneity, and subtle changes in the extent of the whole: the simulation results must fully reflect the various geological and developmental factors encountered, reflect the movement of the underground water, gas, and oil when the injection-production well pattern is adjusted, and reflect the injection-production well pattern adjustment and its effects on the distribution and influence of water, oil, and gas, at the same time, considering the power and capacity of the computer available (Zhang and Xie 2011). The grid type of G393 model is structured corner point grids, uses two $(m+1) \times(n+1)$ rules topology control surfaces to generate unit structure. In the middle, each unit's top and bottom boundary is defined by sliding line, adjacent to the interface between the grid by irregular connection. Conductivity between the grid blocks is calculated using fluid properties, rock properties, fluid rock interaction between two grid blocks and connected to the grid geometry direction, the formula is as follows:

$T_{a}=\left(\frac{A K}{h}\right)_{a v} \times\left(\frac{K_{r a}}{\mu_{a} B_{a}}\right)_{a v}=\operatorname{TRAN}\left(\frac{K_{r a}}{\mu_{a} B_{a}}\right)_{a v}$

where $a$ is one phase of oil, gas and water; $T_{a}$ is unidirectional conductivity of phase $a ; K$ is the absolute permeability; $A$ is contact area of the adjacent grid; $h$ is distance of adjacent mesh centre in the direction; $\mu_{a}$ is viscosity of phase $a ; K_{r a}$ is relative permeability of phase $a$; $B_{a}$ is volume factor of phase $a$

In this 3 -d geological model, $10 \mathrm{~m} \times 10 \mathrm{~m}$ corner point grids were used in the plane lying longitudinally to the individual development of small strata units: this was divided into nine separate flow units. The even-numbered layers allowed no seepage and represented a stable shale layer between the sand strata (Fig. 2).

\section{History matching of the development of the gas reservoir}

To test the reliability of the three-phase, 3-d numerical simulation model, a 5-year production history of the G393 gas reservoirs was modelled. The main indicators were: gas reservoir pressure, gas reservoir gas production, and the gas reservoir oil and water production rates. G393 gas reservoir numerical simulation process is shown in Fig. 3.

Gas reservoir numerical simulation result is shown in Fig. 4. Analysis the simulation results can be obtained that the difference between the results of computer simulation (continuous line) and gas reservoirs' actual production index (point) is small. There is a little difference in the development period between December 2006 and December 2007, that may be due to the well pattern adjusted more frequently in this time period; continuous production measure changes lead to instabilities fitting, affecting the fitting precision. On the whole, the trend remained the same between the two values, the established three-phase, 3-d model did match actual gas reservoir behaviour, so it could be used to simulate and predict changes therein (Fig. 4).

\section{The effect of the oil rim on gas storage injection and production}

The development history of the G393 fault-block condensate gas reservoir showed that they developed the faultblock oil rim and ring contact parts at the same time, but since there was insufficient control at the oil-gas interface,
Fig. 2 3-d geological model used for meshing

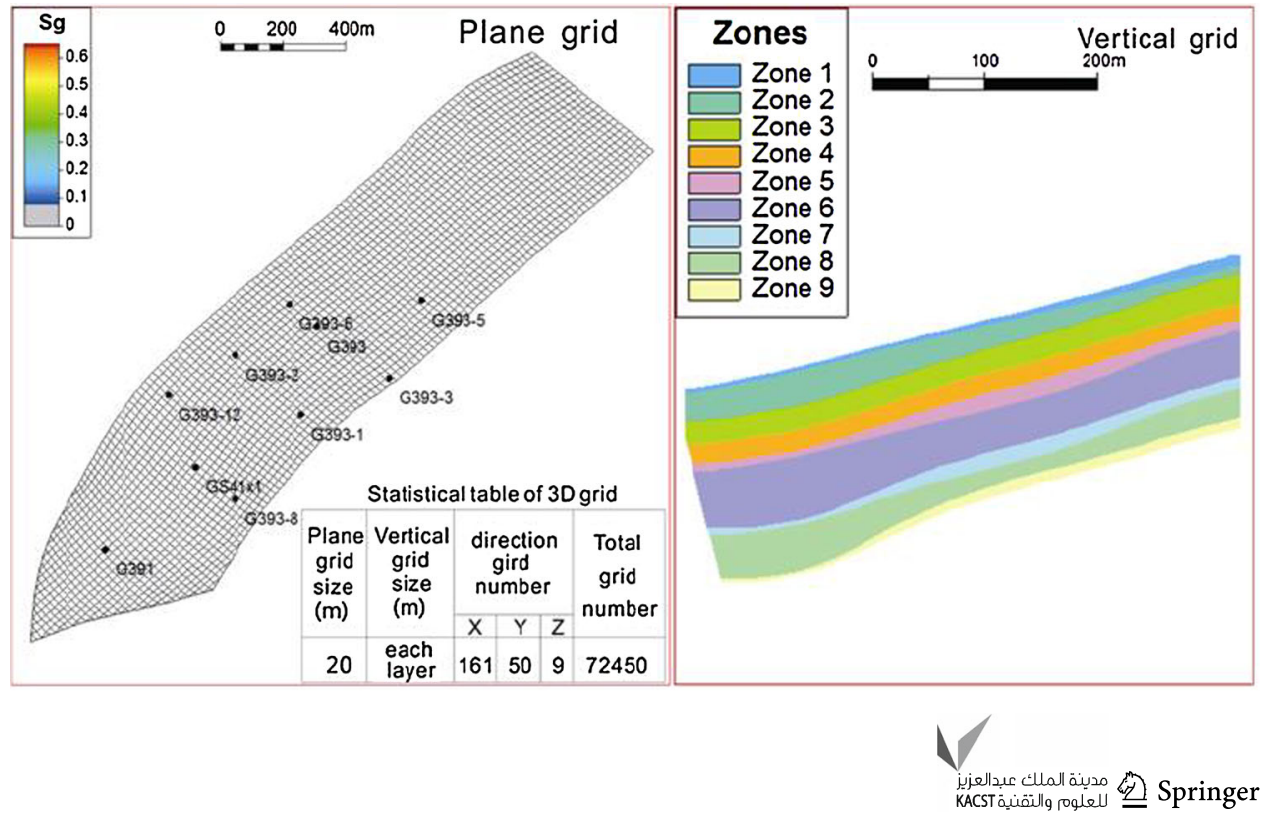


Fig. 3 G393 gas reservoir numerical simulation process

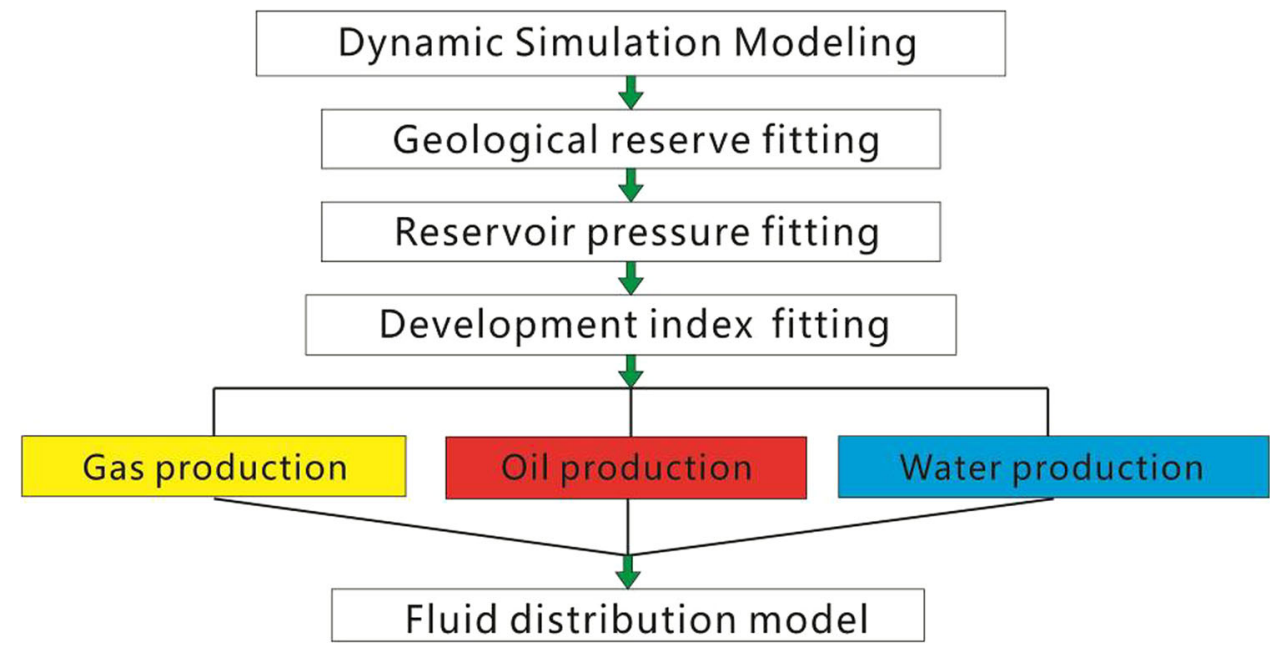

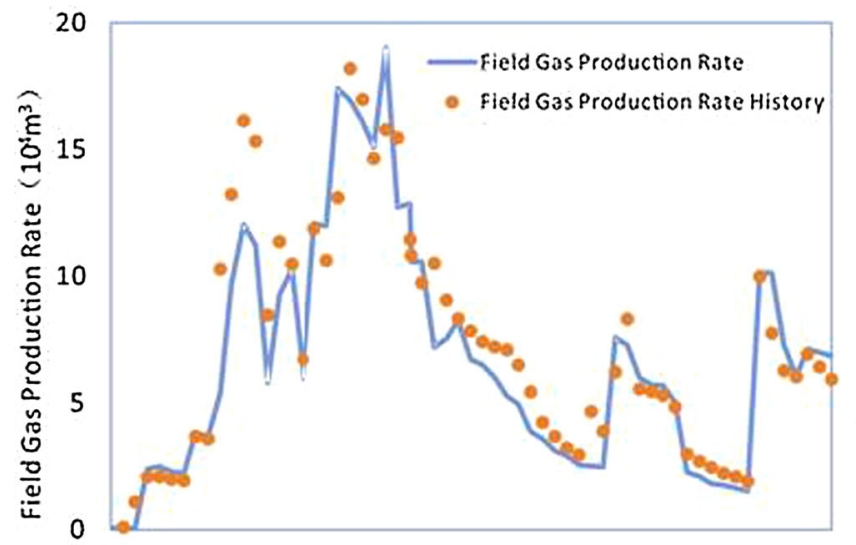

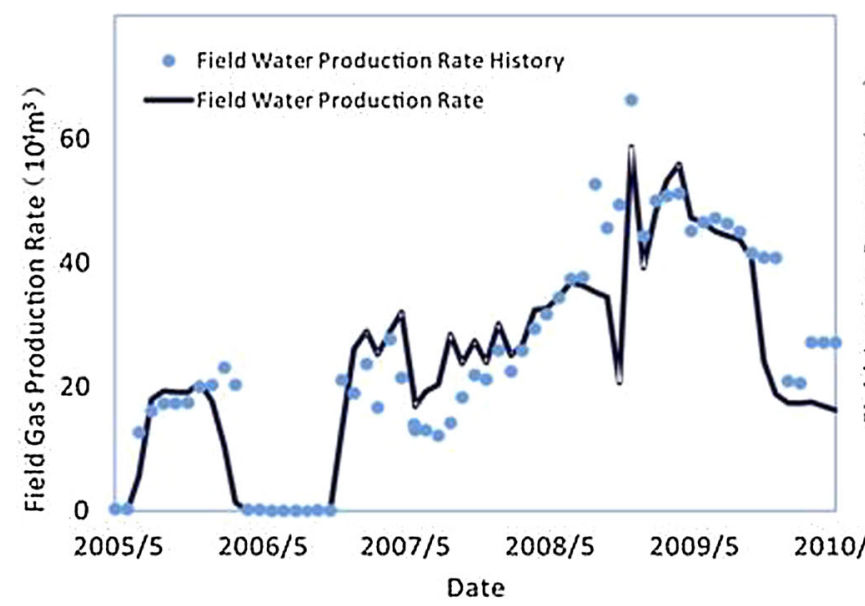

Fig. 4 Gas reservoir production history matching

gas channelling occurred, as well as a significant decline in the production capacity of the oil and gas wells. During its development, to add to the underlying energy output, water-injection development policy was used in the oil rim zone. The relationship between the oil and water distributions is complex: if the gas storage were to be rebuilt, it
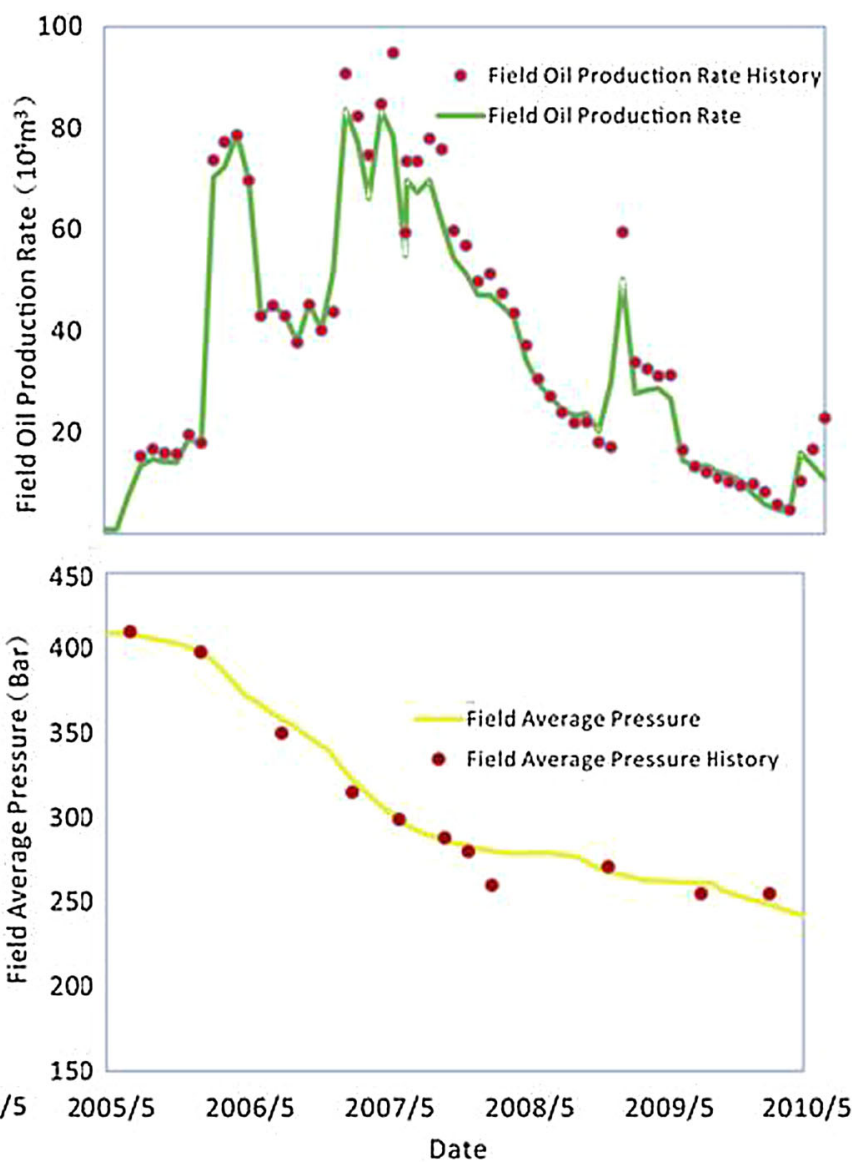

must impact the injection volume and gas recovery therefrom and was not conducive to the smooth and efficient operation of the underground gas storage. Therefore, to enact those control measures needed to reduce the effect of these disadvantages, an understanding of the behaviour of the oil rim, as it affects gas storage, was sought. 
Table 1 The basic fluid properties table of gas, oil and water

\begin{tabular}{|c|c|c|}
\hline \multicolumn{3}{|l|}{ Crude oil properties } \\
\hline \multirow[t]{2}{*}{ Density $\left(\mathrm{g} / \mathrm{cm}^{3}\right)$} & Reservoir & Surface \\
\hline & 0.8931 & 0.7561 \\
\hline \multirow[t]{2}{*}{ Viscosity (mPa s) } & Reservoir & Surface \\
\hline & 10.57 & 0.772 \\
\hline Solidification point $\left({ }^{\circ} \mathrm{C}\right)$ & 35.7 & \\
\hline Compression factor $\left(10^{-4} \mathrm{MPa}^{-1}\right)$ & 8.575 & \\
\hline Saturation pressure (MPa) & 37.51 & \\
\hline \multicolumn{3}{|l|}{ Natural gas properties } \\
\hline Relative density & 0.687 & \\
\hline The content of ethane $(\%)$ & 76.57 & \\
\hline The content of ethane $(\%)$ & 7.68 & \\
\hline \multicolumn{3}{|l|}{ Formation water properties } \\
\hline Water type & $\mathrm{NaHCO}_{3}$ & \\
\hline Total mineralization degree $(\mathrm{mg} / \mathrm{L})$ & $12,778-20,452$ & \\
\hline The content of $\mathrm{CL}^{-}(\mathrm{mg} / \mathrm{L})$ & $5539-11,238$ & \\
\hline \multicolumn{3}{|l|}{ Temperature and pressure system } \\
\hline Initial formation pressure (MPa) & 41.75 & \\
\hline Pressure coefficient & 1.28 & \\
\hline Formation temperature $\left({ }^{\circ} \mathrm{C}\right)$ & 129.8 & \\
\hline Geothermal gradient $\left({ }^{\circ} \mathrm{C} / 100 \mathrm{~m}\right)$ & 3.61 & \\
\hline
\end{tabular}

The presence or absence of oil rim impact mechanism of gas storage

The original state of G393 gas reservoir is a condensate gas reservoir with oil ring, the original gas-oil contact depth is $-3257 \mathrm{~m}$, and the water-oil contact depth is $-3327 \mathrm{~m}$. It can be obtained through the 3D modelling calculation: the oil rim pore volume is about $58.42 \times 10^{4} \mathrm{~m}^{3}$, the gas cap pore volume is about $129.09 \times 10^{4} \mathrm{~m}^{3}$, the pore volume of the active water body is about $182.65 \times 10^{4} \mathrm{~m}^{3}$. The gas, oil, water pore volume ratio is about $2: 1: 3$, therefore, it is a weak edge water condensate gas reservoir. The basic fluid properties of gas, oil and water are shown in Table 1.

Compared with the same type of condensate gas reservoir, the extent to which the oil rim affected gas storage injection and production was unknown. To reveal this, we used the previously established 3-d, three-phase model as the basis for gas storage injection-production capacity predictions which assumed the existence of oil rim. In this simulation: the gas was only present at the gas-oil interface, there were no three-phase coexistence reservoirs when the field was in its original condition (Kilincer and Gumarch 2000). Figure 5 shows the two gas reservoir models used.
Fig. 5 The two numerical simulation models used




Table 2 summarises the analysis simulation parameters used along with a series of simulation parameters used in the numerical simulation of the process: consistent injection and production parameters were used in each of the two models to compare the differences in their results.

In the two prediction schemes, gas was injected into the formation until the formation pressure was restored to its original value: the cumulative injection curve and stress change curve are plotted in Fig. 6. From the graph and its horizontal ordinate $\mathrm{A}, \mathrm{B}, \mathrm{C}$, and $\mathrm{D}$ are points at which the oil rim lies at the bottom of the condensate gas reservoir, the injection rate and injection volume had decreased to a certain extent, but the pressure rose faster than in a pure gas reservoir. Under the same injection conditions and at the same formation pressure, the condensate gas reservoir, with an oil rim, needed about 68 days to develop, and the peak pressure of pure condensate gas reservoirs was reached in approximately 92 days: the accumulation of the final injection volumes were $1.33 \times 10^{8}$ and $1.76 \times 10^{8} \mathrm{~m}^{3}$, respectively.

Figure 7 shows the mechanism underpinning the behaviour of this underground gas storage injection-production.
In the pure condensate gas reservoir, the gas promoted a uniform transverse distribution during injection. The gas was pushed into the water (a vertical distance of $36 \mathrm{~m}$, and a $260 \mathrm{~m}$ plane distance) and did not form a serious fingering pattern when gas was injected into the formation until the formation pressure reached its original value. The gas velocity decreased, and the flow path occupied a shorter distance (a vertical distance of $13 \mathrm{~m}$, and an $8 \mathrm{~m}$ plane distance) with the oil rim of this condensate gas reservoir during the injection process due to the blocking effect of the oil rim, especially after the gas entered the oil rim and dissipated therein which induced significant lateral deviation errors: a single direction dash phenomenon would have been more serious, but the fluid had not yet spread to cover the entire oil rim area at that stage.

\section{Oil rim recovery degree impact on underground gas storage}

The aforementioned research showed that the presence of the oil rim affected the injection of gas in this underground storage, and that was not conductive to the spread of the gas

Table 2 Analysis simulation parameters

\begin{tabular}{lllll}
\hline Injection well number & Injection position & Injection rate $\left(10^{4} \mathrm{~m}^{3} /\right.$ day) & Maximum injection pressure (bar) & Target pressure (bar) \\
\hline 5 & The top & 50 & 46 & 410 \\
\hline
\end{tabular}



Fig. 6 The injection parameters for block G393 with an oil rim and a pure condensate gas reservoir 
Case 1: Gas-Water reservoir

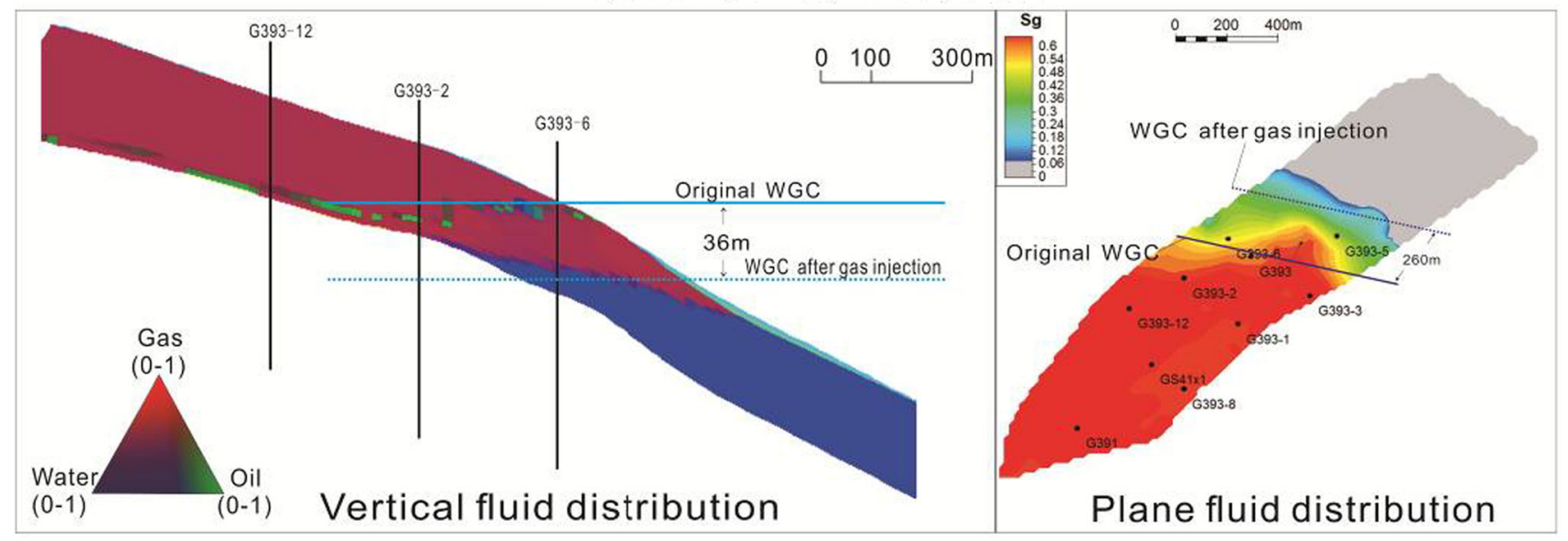

Case 2: Oil-Gas-Water reservoir

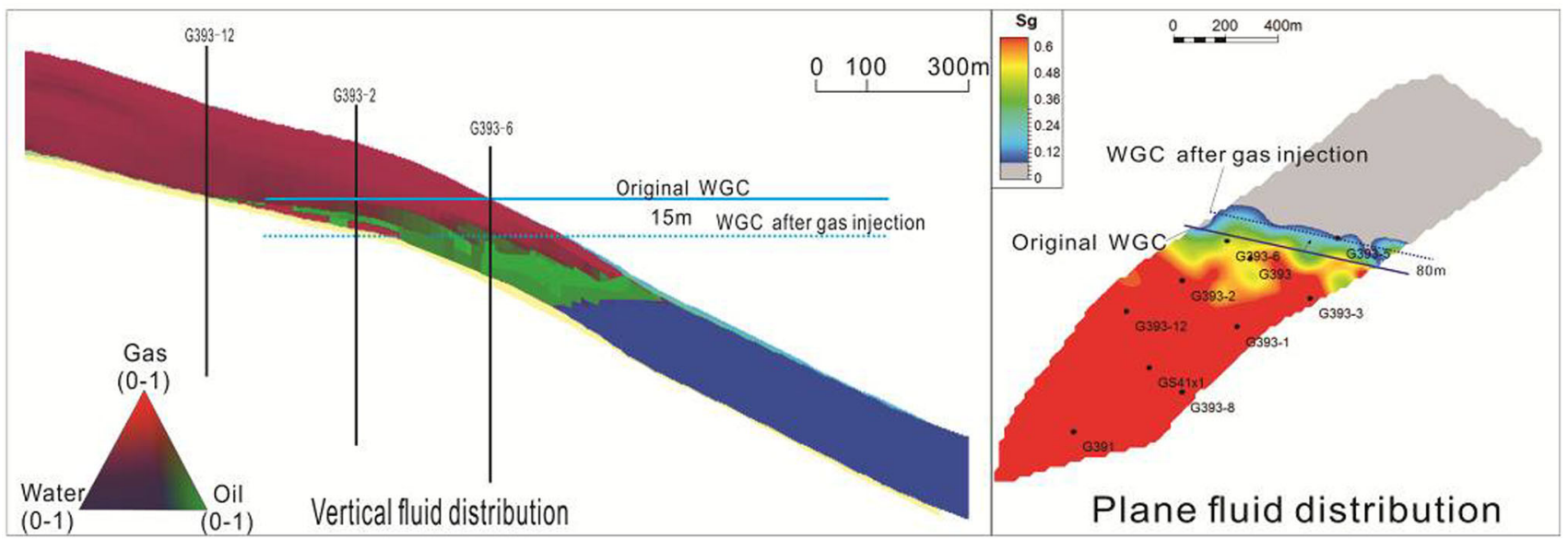

Fig. 7 The injection-production behaviour: oil rim effects on underground gas storage

Table 3 Numerical simulation parameters

\begin{tabular}{lllll}
\hline $\begin{array}{l}\text { Oil rim recovery } \\
\text { programme }\end{array}$ & $\begin{array}{l}\text { Gas injection period } \\
\text { (months) }\end{array}$ & $\begin{array}{l}\text { Gas production period } \\
\text { (months })\end{array}$ & $\begin{array}{l}\text { Injection rate } \\
\left(10^{4} \mathrm{~m}^{3} / \text { day }\right)\end{array}$ & $\begin{array}{l}\text { Maximum injection pressure } \\
\text { (bar) }\end{array}$ \\
\hline $0-55 \%$ & $8(16$ Mar. to 15 Nov. $)$ & 4 (16 Nov. to 15 Mar.) & 50 & 46 \\
\hline
\end{tabular}

therein. The first issue facing the operators of this type of gas reservoir was that it produced as much of the remaining oil in the underground reservoir as possible, and vacated sufficient rock pore volume to provide more gas storage. The gas pressure increased as injection progressed; the degassed oil will reach a second saturation during development of the gas reservoir, as it absorbs some of the dissolved gas. An allied viscosity reduction, enhancing the flow properties, meant that this oil could be easily recovered.

Therefore, the main task for this injection-production well near the oil rim was to extract oil early in the gas storage injection-production cycle.

To simulate the impact of the recovery from the oil rim to the extent of injection-production process gas storage, this research used the design of different schemes to numerically simulate underground conditions. Different degrees of recovery from the oil rim oil wells in the vicinity of the oil rim were simulated. Injection-production wells, using the original development wells, and injectionproduction parameters derived from the use of the injection-production parameters of each well in the study scheme were predicted from the beginning for each corresponding degree of recovery (Fu et al. 2007). Wells G393-2 and G393-3 were predicted to be best stopped when their production gas-oil ratio exceeded 100,000: thereafter, number of cycles to be run was compared. Table 3 shows the parameters used in this numerical simulation. 
Fig. 8 The relationship between the oil production cycle and oil rim recovery

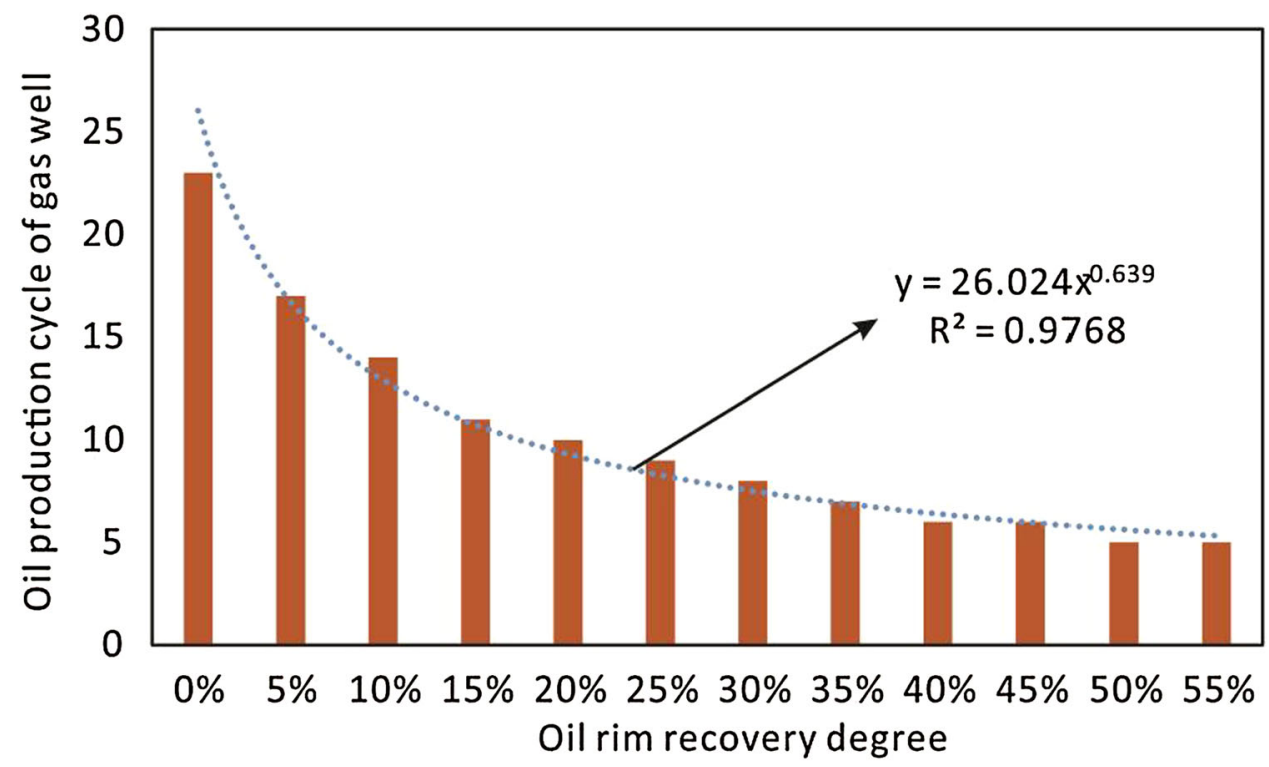

Table 4 The forecast injector-producer parameter table for the underground gas storage operation plan

\begin{tabular}{llllll}
\hline Well area & $\begin{array}{l}\text { Well } \\
\text { number }\end{array}$ & $\begin{array}{l}\text { Gas injection period } \\
\text { (months) }\end{array}$ & $\begin{array}{l}\text { Gas production period } \\
\text { (months) }\end{array}$ & $\begin{array}{l}\text { Injection rate } \\
\left(10^{4} \mathrm{~m}^{3} / \mathrm{day}\right)\end{array}$ & $\begin{array}{l}\text { Maximum injection pressure } \\
\text { (bar) }\end{array}$ \\
\hline $\begin{array}{l}\text { Gas cap } \\
\text { Gas oil } \\
\text { contact }\end{array}$ & 2 & 8 (16 Mar. to 15 Nov.) & 4 (16 Nov. to 15 Mar.) & 50 & 46 \\
Oil rim & 3 & & 35 & \\
\hline
\end{tabular}

The numerical simulation results shown in Fig. 8 show that with increasing recovery from the oil rim, the production period of the well near the gas storage zone within the oil rim was gradually shortened, and the oil rim recovery showed a power-function relationship therewith; the magnitude of this change decreased and gradually stabilised once the extent of the oil rim recovery reached $25 \%$. Therefore, when the oil rim recovery was between 25 and $30 \%$, the conditions for renovation of underground gas storage were optimal.

\section{Effects of the oil rim on G393 underground gas storage operation analysis}

Until the reconstruction of this gas storage, $61.03 \%$ of the condensate gas in the geological reserve was recovered, and $20.81 \%$ of the condensate oil and crude oil were recovered. According to the principles guiding underground gas storage reconstruction, the degree of recovery of condensate gas was suitable for the rebuilding of this underground gas storage (the best recovery rate was $60 \%$ ). The extent of the oil recovery was not very high. If calculated according to the forecast results, at least 10 injection-production cycles could be produced in the reservoir in which crude oil was present: for the operation of the gas storage, this was without doubt a very unfavourable factor. Hence, the need for this study is on the basis of the existing oil rim recovery, as designed for the rapid recovery of gas storage injection-production well patterns, so that the quickest underground gas storage operation could be brought about. There are three main principles guiding the design of such schemes (Chen and Tan 2001):

1. Increase the degree of control of the well pattern in the oil rim region, especially near the oil-gas interface where corresponding control wells should be used.

2. The volume of injected gas should be controlled during injection into the injection-production well in the oil rim region, in this way, there is sufficient time to mix the injected gas and crude oil, thus increasing the crude oil quadratic saturation.

3. To prevent the formation of a pressure drop funnel (a result affecting the crude oil use area), the differential pressure must be controlled during production recovery. 
Fig. 9 Designed well positions for the numerical simulation of the G393 underground gas storage

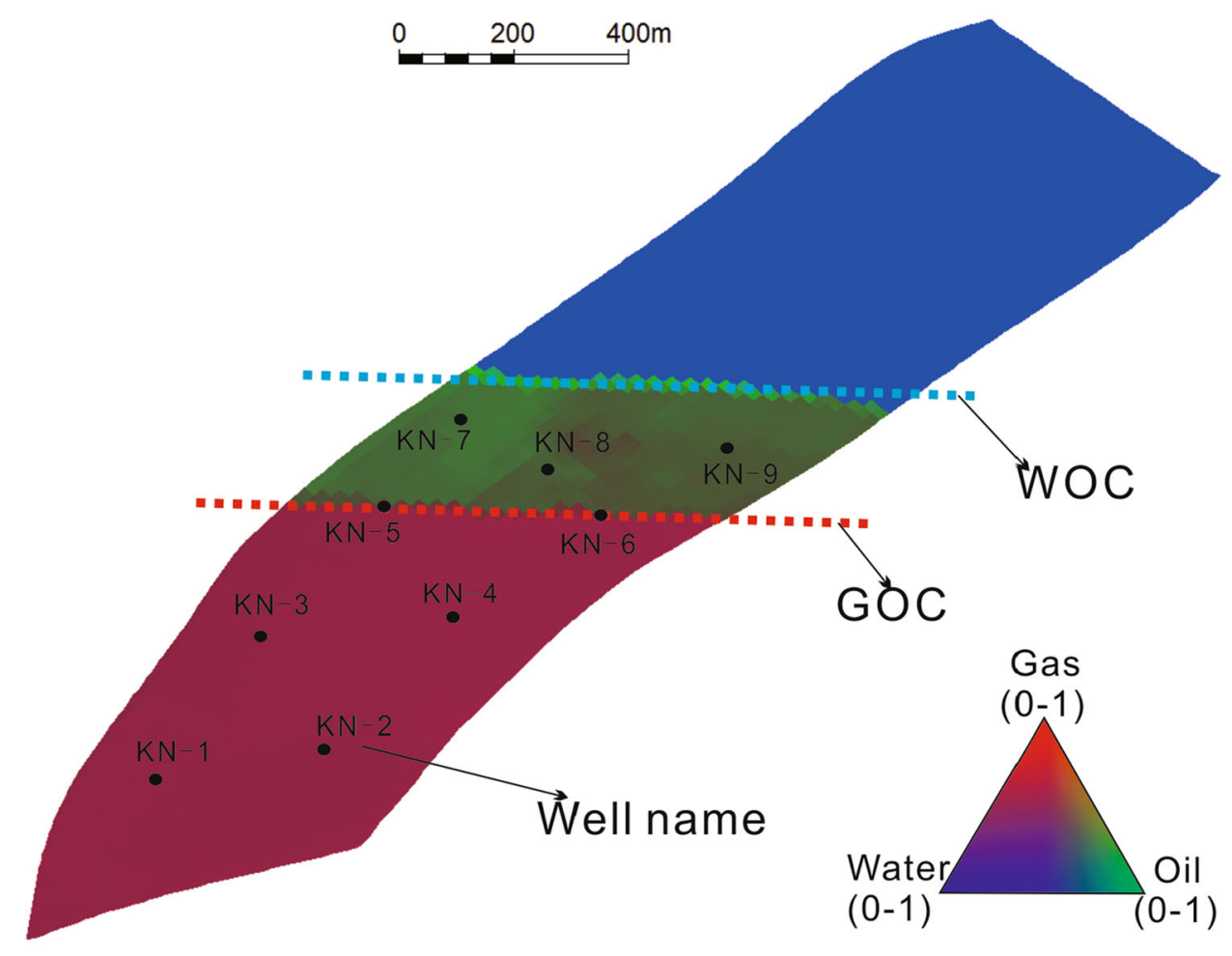

Fig. 10 Numerical prediction of the cumulative recovery of crude and gas oil as a ratio curve for the G393 underground gas storage

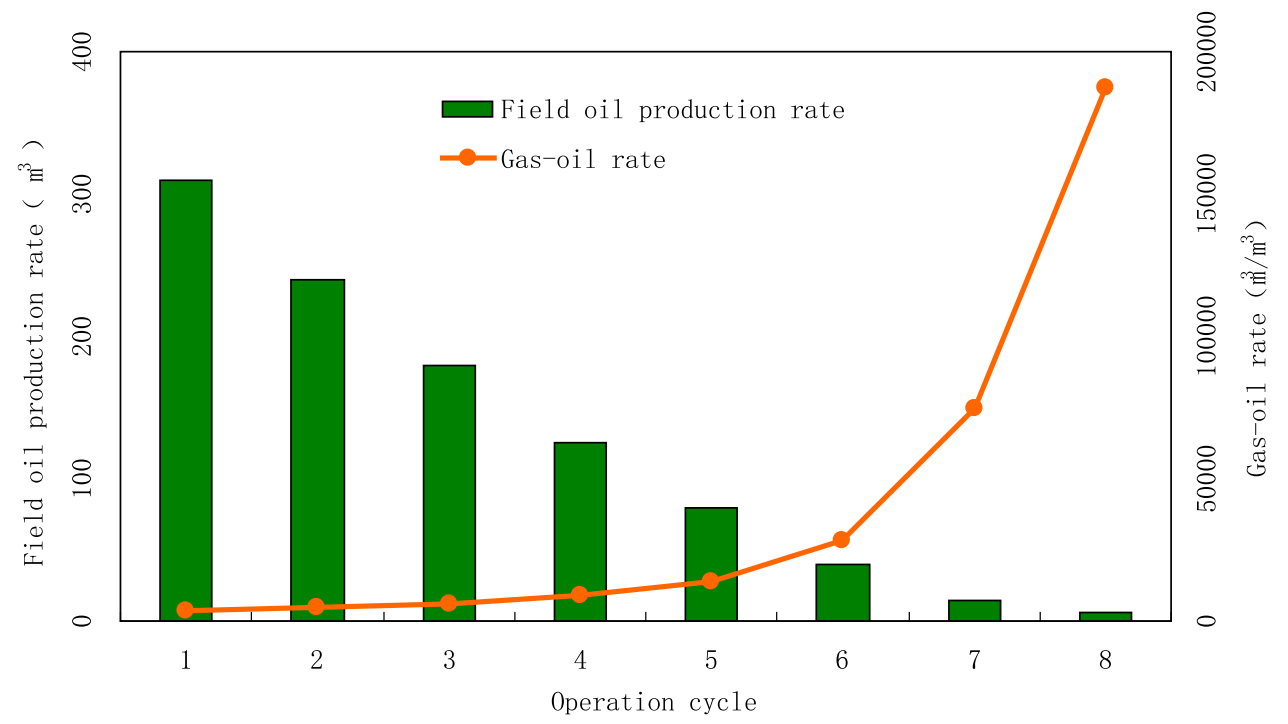

By adhering to these principles, we designed an injection-production well pattern for the G393 underground gas storage: there were nine wells in all (four in the area of the gas cap, two in the oil-gas interface, and three within the oil rim). Table 4 shows the injection parameters used therein.

Figure 9 shows well positions used in these numerical simulations.

Figure 10 shows the numerical simulation forecast of the cumulative recovery of crude and gas oil in the form of a ratio curve for the operation of the G393 underground gas storage: it can be seen that, over the operating cycles, the oil in the oil rim was produced continuously, oil recovery gradually decreased until about the tenth cycle, and the production gas-oil rate reached 100,000 , at a recovery efficiency reaching $75 \%$, the crude oil was largely emptied from the reservoir space, the operational efficiency of gas storage improved, and the capacity and working period were also gradually stabilised. 


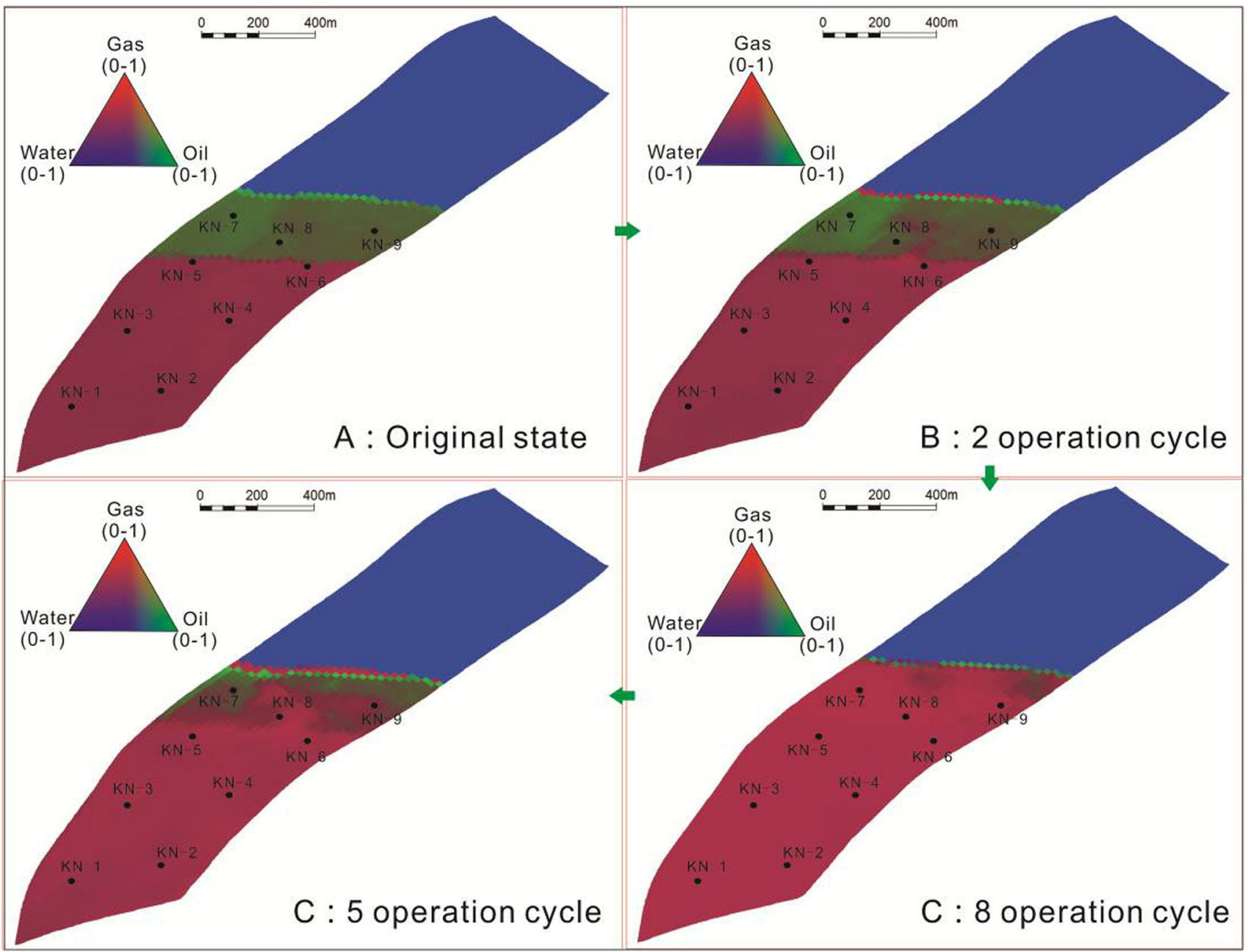

Fig. 11 Changes in oil saturation in the oil rim during the operation of the G393 underground gas storage

Figure 11 shows the change in oil saturation in the oil rim during the operation of the G393 underground gas storage: as the underground gas storage increased over several operational cycles, the oil saturation within the oil rim decreased quickly, crude oil around the operation wells showed a high degree of recovery, the pore ratio was high, the local area around the edge, or the local area near the fault was changed due to reservoir or gas injection, there was little crude oil in the pore body, but this had less effect on gas storage capacity and the operations as a whole (Zhao 2000; Tan and Lin 2008). On the whole, about eight cycles later, the influence exerted by the oil rim had diminished, and the gas storage was operating smoothly.

\section{Conclusions}

According to the extent of the effect of the oil rim on production, and the influencing mechanism of the presence, or absence, of the oil rim on oil injection and production from this gas storage, the following main conclusions were drawn:

1. In the presence of the oil rim, the injected gas spread and promoted a significant lateral deviation error; a single direction of penetration would have been more deleterious and would have reduced the gas injection rate and amount of gas injected to nearby wells, and it would have affected the diffusion velocity of gas in the water. In the G393 underground gas storage, the gas was used to drive the water forward over a reduced distance of $180 \mathrm{~m}$ (plane) and $23 \mathrm{~m}$ (longitudinal).

2. The oil rim, with regard to the crude oil recovery ratio, can directly affect the operating efficiency of such an underground gas storage. When the recovery factor was reduced, the production period gradually increased. According to the numerical prediction, an oil rim recovery of $25-30 \%$ was optimal for the renovation of this underground gas storage.

3. Under low oil recovery conditions, during reconstruction of this underground gas storage, we can increase 
the injection-production well flow rate within the oil rim for a more rapid resource recovery: this can vacate underground reservoir pores and improved the efficiency of gas storage. In addition, the edge of the well can be used as an inspection well and a drainage well during the later stages of operation, thus saving money.

Acknowledgments The authors would like to thank the workers of Dagang Oilfield of Petrochina for supplying researching data.

Funding sources This article is funded by two foundations: Project (51504143) supported by the National Natural Science Foundation of China; Project (41172109) supported by the National Natural Science Foundation of China; Project (ZR2014DP012) supported by the National Natural Science Foundation of Shandong province.

Open Access This article is distributed under the terms of the Creative Commons Attribution 4.0 International License (http:// creativecommons.org/licenses/by/4.0/), which permits unrestricted use, distribution, and reproduction in any medium, provided you give appropriate credit to the original author(s) and the source, provide a link to the Creative Commons license, and indicate if changes were made.

\section{References}

Caudle BH, Dyes AA (1958) Improving miscible displacement by gas-water injection. SPE911, pp 213-217

Chen J, Tan Y (2001) Planning and design essentials on natural gas underground storages. Oil Gas Storage Transp 20:13-26
Ding G, Xie P (2006) Current situation and prospect of Chinese underground natural gas storage. Nat Gas Ind 26:111-113

Fu Y, Guo X, Du Z, Liu L (2007) Numerical simulation research on underground gas storage considering fracture deformation. J Southwest Pet Univ 29:92-94

Haln HK, Monger TG (1990) A laboratory study of natural gas HuffPuff. Society of petroleum engineers, SPE21576, pp 85-92

Kilincer N, Gumarch F (2000) Numerical simulation study on mixing of inert cushion gas with working gas in an underground gas storage reservoir. Energy Sources 22:869-879

Kurihara M et al (2000) Development and application of underground gas storage simulator. In: Proceedings of SPE Asia-Pacific conference on integrated modelling for asset management, pp 339-352

Li T, Zhang Y (2000) Construction and development of underground gas storage. Oil Gas Storage Transp 19:1-8

Tan Y, Lin T (2008) Analysis on the single-well capacity of injection/ withdrawal in underground gas storage reservoir. Oil Gas Storage Transp 27:27-29

Udegbunan EO et al (1994) Geological characterization and 3D visualizations of the gas storage reservoir at Hillsboro field, Montgomery Country, IL. In: Proceedings-SPE eastern regional conference and exhibition, pp 5-30

Wang J et al (2014) Initial gas full-component simulation experiment of Ban-876 underground gas storage. J Nat Gas Sci Eng $18: 131-136$

Wozinak DA, Wing JL, Schrider LA (1997) Infill reserve growth resulting from gas Huff-n-Puff and infill drilling - a case history. SPE39214, pp 23-36

Zhang J, Xie J (2011) Oil field development geology. Petroleum Industry Press, Beijing, pp 1-35

Zhao S (2000) Underground gas storage injection and production technology. Petroleum Industry Press, Beijing, pp 1-12 